\title{
The Methodologies of Neuroeconomics
}

\author{
Glenn Harrison \\ Georgia State University \\ gharrison@gsu.edu \\ Don Ross \\ University of Cape Town \\ don.ross@uct.ac.za
}

\section{$\underline{\text { Abstract }}$}

We critically review the methodological practices of two research programs which are jointly called 'neuroeconomics'. We defend the first of these, termed 'neurocellular economics' (NE) by Ross (2008), from an attack on its relevance by Gul and Pesendorfer (2008) (GP). This attack arbitrarily singles out some but not all processing variables as unimportant to economics, is insensitive to the realities of empirical theory testing, and ignores the central importance to economics of 'ecological rationality' (Smith 2007). GP ironically share this last attitude with advocates of 'behavioral economics in the scanner' (BES), the other, and better known, branch of neuroeconomics. We consider grounds for skepticism about the accomplishments of this research program to date, based on its methodological individualism, its ad hoc econometrics, its tolerance for invalid reverse inference, and its inattention to the difficulties involved in extracting temporally lagged data if people's anticipation of reward causes pre-emptive blood flow.

Keywords: neuroeconomics, Gul and Pesendorfer, ecological rationality, neurocellular economics, MacGyver econometrics, reverse inference, pre-emptive blood flow

JEL codes: A12, B41, C51, C81, C91, D03, D87

Neuroeconomics has arisen quickly as a subfield within economics, but does not exhibit a unified methodology. The general distinction we find most useful is between what Ross (2008) calls "neurocellular economics" (NE) and "behavioral economics in the scanner" (BES). We organize our critical assessment below in terms of these methodologies. Although we are generally skeptical about BES, our identification of problems with NE that need more attention are intended constructively.

\section{The Methodological Backlash Against Neuroeconomics}

Starting about 1870, a dominant methodological trend in economic theory was the progressive severance of direct psychological commitments. This process involved three principal milestones:

- The generalization of all forms of value by reference to an abstract concept of utility.

- The recognition that convexity of demand need not be grounded in a psychological principle of diminishing marginal satisfaction, but could be derived from anodyne assumptions about substitutability and budget constraints. 
- The popularity of revealed preference theory, which is ironically about the elimination of preferences, conceived as latent states of mind, in favor of attention to the logical consistency of observable choices.

In light of this history, it would be surprising if most economists were prepared to incautiously swallow the suggestion that we can do better economics by examining people's brains. And so it is not surprising that the appearance of several brash and sometimes messianic ${ }^{1}$ research programs trading under the banner of "neuroeconomics" has begun to provoke a backlash. Harrison (2008) and Bernheim (2009) both concede possible, albeit modest, potential contributions that brain studies could offer to economics. Gul and Pesendorfer (2008) (GP) concede nothing at all; they thereby usefully define an extreme limit point with respect to the economist's assessment of neuroeconomics, against which less uncompromising positions can be efficiently developed. We confine attention here to selected aspects of GP's critique that set up general points we make later.

According to GP, psychological hypotheses and empirical findings might usefully "inspire" economists' hypotheses, but economic models should include only variables that condition what an agent chooses and none that condition how an agent chooses. This is because the task of positive economics is to predict choices as functions of changes in incentives and opportunity sets. GP do not derive this claim from transcendental insight into the true domain of economics. Rather, they believe it to be a sociological fact that most economists are not professionally concerned with variables for psychological processes, and will continue to maintain this attitude because the generalizations they seek about the influences of incentives and opportunities on choices are not sensitive to differences in such variables.

GP presumably do not think that choices are structureless Sartrean actes. They no doubt suppose that they are computational processes of some sort, conditioned on underlying valuations (which may themselves have resulted from prior choices). Their claim is that the economist does and should leave the processing details inside black boxes. This implies the view that a model that relates valuations and opportunities to outputs of choice processes is a description of a class of computations in reduced form. Harrison (2008) points out that GP's examples imply a suggestion that all economic models should be exclusively given in reduced form, and should never be structural. This, he observes, is something one could only imagine at great theoretical distance from the actual testing of models against empirical evidence, particularly experimental evidence. As the cost of computing power has fallen, structural models have become increasingly common in all areas of economics except the most airless reaches of theory; this has in turn driven a surge of innovation in econometric techniques. An argument based on economists' practice rather than on dogma about its 'rightful' domain cannot ignore this. Economics departments certainly don't let their graduate students ignore it.

In fact, GP allow that economic models should include variables that constrain opportunity sets, such as interest rates. An interest rate is a kind of processing state variable, describing

\footnotetext{
${ }^{1}$ Witness the readiness of some neuroeconomists to blithely draw revolutionary conclusions from small neuroimaging studies. For example, Knutson et al (2007) consider fMRI data from 26 subjects choosing purchases, and on this basis announce that economists have been mistaken in modeling consumers as minimizing opportunity costs.
} 
trajectories of expected future transactions, but which aggregates the choices of many agents. What GP consider alien to economics about neural (and other psychological) processing states, therefore, must not be that they are processing states, but that they are internal to the agent. The black box that the economist is specially forbidden to open is in fact the skull cavity.

Proposed as a general principle, this is a mere prejudice. In particular, it offers no sound basis for denying the validity of the NE branch of neuroeconomics. This program is identified with Glimcher (2003) and colleagues, and uses the technical resources of economic theory to understand the mechanisms by which brains comparatively evaluate alternative possible states that share no common dimensions describable in terms of sensory modalities or neurochemical response profiles. Glimcher (2009) calls this "subjective value," though we suggest that "value in the brain" would invite fewer misinterpretations. The program's viability and potential importance rest on an empirical hypothesis that dopamine signals in the ventral striatum and medial prefrontal cortex constitute a "common currency" of reward that has many properties in common with the mainstream economist's concept of utility. If this hypothesis is correct, then neuroscientists might usefully exploit a century's progress by economists in studying utility to model valuation in the brain.

We see no reason why any economist, however sure they might be that psychological variables aren't relevant to studying the traditional domain of economics, should resent the borrowing of economic theory to model other domains. No one, for example, argues for baning ecologists from using cost-benefit analysis. Of course, one might follow up this point by asking why, if economic theory should turn out to be the main modeling technology for the neural reward circuit, this shouldn't lead us to say that the domain of economics had been widened. ${ }^{2}$ But this "issue" looks entirely semantic.

A different way in which some theorists have aimed to carry economics "inside" the individual was pioneered by Strotz (1955-56), Schelling $(1978,1980,1984)$ and Ainslie (1992), and has been refined in contributions by Benabou and Tirole (2004), Benhabib and Bisin (2004) and Fudenberg and Levine (2006). All of this work involves explaining behavioral patterns in individual people as equilibria of games amongst sub-personal agents, which might or might not be identified with functional modules of brains, such as those suggested by McClure et al (2004). Gul and Pesendorfer (2001) develop the details of a modeling framework that is explicitly intended to capture the main phenomena which interest the "multiple self" tradition (procrastination, addiction, and other forms of intertemporal irresolution) without positing any sub-personal agents. Thus, whatever view one might take of the comparative merits of these approaches, one cannot in this instance accuse GP of resting their negative case on arbitrary restrictiveness about what economists should and shouldn't get up to. Note that Glimcher (2009) also explicitly rejects multipleselves models, at least insofar as the sub-personal selves in question are identified with neural modules.

We refrain from declaring for one of the dogs in this fight. Empirical data on the dynamics of intertemporal consumption are not yet sufficiently rich to favor any one model over its alternatives. Instead, we note an irony in this debate: the fact that GP make a methodological

${ }^{2}$ This is the attitude of Ross (2005), Ross et al (2008), and Caplin and Dean (2008). 
fetish out of choice at the level of the individual personal agent renders them bedfellows of precisely the BES school of neureoconomics they attack. BES consists in repeating protocols that putatively demonstrate human "irrationality" under neuroimaging, and trying to show how "anomalies" in rational choice have their origins and explanations in framing effects that result from the computational processing architecture of the brain. These behavioral economists strike the attitude of rebels against "mainstream" or "neoclassical" economics and revealed preference analysis, and promote neuroeconomics as a core part of the alternative program. Camerer, Loewenstein and Prelec (2005) provide a useful survey of work in this area, unfortunately presented as if it constituted the whole of neuroeconomics.

We share the skepticism of GP about BES. But we believe that a stubborn refusal to think about the processes that support relationships among incentives, opportunities and choices is a self-defeating way of promoting this skepticism. It concedes to the advocate of BES that what economics is fundamentally about are individual people arriving at and applying valuations all by themselves. This ignores what Smith (2007) refers to as the ecological nature of economic rationality. Ecological rationality emphasizes the extent to which people approximate consistent, "old-fashioned" economic rationality, not because of computational marvels they achieve with their raw brains, but by means of what the philosopher Clark (1997), following Hutchins (1995), calls cognitive "scaffolding." This consists of external structures in the environment that encode culturally accumulated information and constrain and channel behavior. Economists are familiar with social scaffolding under the label of "institutions."

Our point here is not that economists have been citing Clark or Hutchins, or generally appreciate the full power of their conceptual contributions. Philosophers might have been expected to notice the connection, but we speculate that they have largely missed it because economists' examples of institutions are typically official entities with proper names, such as the Federal Reserve, or explicit legal structures, rather than the ubiquitous and informal guideposts to cultural practice and coordination that Clark and Hutchins emphasize. However, we can see no conceptual distance at all between scaffolding and Smith's 'ecological rationality'; Wilcox (2008) makes the same point.

Ecological rationality is at the centre of some of the most discussed and cited recent work in applied economics. For example, Gode and Sunder (1993) model the behavior of simulated agents with "zero intelligence" that simply follow the rules of a double auction experiment subject to budget constraints. That is, sellers do not offer to sell for more than their marginal cost, and buyers do not offer to buy for more than their maximum willingness to pay; otherwise, they bid randomly, constrained in the other direction only by some reasonable upper bound or by zero. The efficiency of these simulated markets parallels that achieved by human subjects, suggesting that the efficiency of the outcomes results from the ecological rationality of the institutional rules, rather than relying on deliberatively and individually rational agents. Sunder (2003) discusses generalizations of this striking result, and a broader range of applications in economics.

To illustrate the contrast between ecological and naively individualistic rationality, imagine an investor deciding how often she should churn her portfolio. One might first imagine her modeling the financial market, including a representative agent with rational expectations. This agent gathers time-indexed data on prices and returns, and calculates an average churn rate, variance and signal-response rule from which to construct a policy that maximizes her 
expected lifetime earnings. Though this is how economists might aim to discover the investor's policy, they know this does not describe the approach of the actual, typical person. What she does instead is exploit the fact that she operates within a network of public, normative signals. The transaction fees charged by licensed brokers vary within narrow ranges. These ranges systematically co-vary with volatility in asset prices, dividend rates, and opportunity costs of investments in the assets in which the brokers traffic. Our agent might, in ignorance, begin by suffering abuse at the hands of her broker and churning too much.

Fortunately, her environment is likely to be full of signals, including institutionally encoded second-order signals about the relative reliability of various first-order signals, that provide her with a good chance of discovering this. She might over-react and for a time churn too little. But she also may have access to signals about the earnings of other people whose situations are similar to hers. If they consistently do better than she does, it may occur to her that when her new broker tells her that she is holding assets for too long, this one might not be trying to exploit her. Ultimately, our agent's behavioral transaction rate might range close to what the economist formally modeling her situation would recommend.

We can imagine a psychologist studying the investor in detail over the course of years and predicting her specific behavior more exactly than is possible using the economist's "as if" approach. If all investors were psychologically identical this might be considered grounds for disinvesting in economists and using the savings to train more psychologists. But there are persuasive grounds for thinking that psychological variance among people is such as to defeat this argument. Each member of a set of investors might use an idiosyncratic learning path and idiosyncratic representations to infer what counts as the same thing at a sufficiently abstract scale of description - namely, the approximately optimal churn rate for a broad range of asset classes and market parameters. In that case, the economists will be in a far stronger position to predict out of sample, and to offer aggregate-scale predictions, than any of the psychologists who have more exact models of types of processing used by individuals. $^{3}$

The moral of this simple - indeed, simplistic - example can easily be taken too far, however. GP write as if we know, in advance of all empirical work, that psychological variation among individuals learning a given economic relationship will have a known distribution, for which we can exactly control in a reduced-form model. This is very often false, in which event work of psychologists or sociologists or neuroscientists might provide relevant evidence in any given case. More importantly, our access to evidence might be limited in such a way that our most practical procedure is to include parameters in our models that allow the data to help us sort a population into sub-populations, each of whose members converge on an economically distinct solution.

Consider, as a real instead of stylized example, the very phenomenon that has motivated the arguments between multiple-self and single-self models of intertemporal consumption, namely, intertemporal discounting. Begin by imagining two limiting cases. In Case 1 each

\footnotetext{
${ }^{3}$ We are not suggesting here that psychologists aren't interested in properties shared across individuals. The point is merely that classifying phenomena by reference to processing variables will generally produce a different partitioning of states and events than classifying them by reference to economic response functions, and in the particular case we are imagining the psychologist's partition will be of finer grain than the economist's.
} 
agent draws a discounting function from a random distribution of mathematically possible forms, but all agents are financially punished by their market institutions to the extent that they depart from exponential discounting at a common rate $x$. Psychologically, these agents are perfectly idiosyncratic. In Case 2 all agents discount identically, but in a way that causes them all to manifest systematic intertemporal preference reversals. GP write as if Case 1 were standard. Here, so far as economic prediction is concerned, psychological processing variables are pure noise. Advocates of BES prefer a methodology that assumes Case 2 to be the norm. These agents evidently face some barrier against learning to create institutional scaffolding that could help them to act more consistently. Perhaps it is their recalcitrant brains that get in their way.

Recent empirical work has shed considerable light on reality with respect to this example. Hypotheses resembling both limiting case have been cleanly rejected. When we study discounting behavior, or any choice process, we have to worry about whether any given agent uses more than one model or 'data generating process' in different domains (Harrison and Rutström (2009); Coller et al. (2009)). When we model any behavioral function in economics we have to account systematically for the individual heterogeneity that we expect a priori from preferences, but which demand formal econometric methods and large sample sizes (Harrison at al. (2002); Harrison and Rutström (2008)). We have learned that discounting in real populations is better described by structural models which allow representation of heterogeneity with respect to curvature of utility functions and with respect to discount rates, than by models that impose a common reduced functional form on everyone. And we also know that exponential discounting usually predominates over hyperbolic discounting, contrary to a common dogma of behavioral economics (Andersen et al. (2008)).

Thus the most empirically robust and informative models of discounting and related behaviors include some processing variables, but only as many as are needed to allow us to estimate a limited set of parameters from data. The process of discovery of these models is economics, not psychology, because it does not discriminate between different hypotheses that would be of major concern to a psychologist. Do majorities of human populations converge on exponential discounting because their brains are naturally disposed to it, or because the social ecologies in which they are immersed train them to do so and induce them to collectively build institutional scaffolding that helps them to keep on track?

Notice that if one were doing psychology, and were investigating the question just posed, one thing one might want to do is wrench subjects out of their scaffolded environments. One way to do this would involve putting them in strange laboratories performing socially novel tasks; or, possibly, to disorient them still more, by making them lie down with their heads in magnets. We could then see if they discounted in ways their public norms would deem confused. There is a non-arbitrary reason to say one is doing psychology rather than economics here: in the context of their natural, culturally-evolved, economies, most of the subjects will not behave this way. This points to a respect in which economics is not merely methodologically autonomous with respect to neuroscience: economic regularities, understood as ecological properties of a certain kind, can causally dominate neural processing properties that would prevail in a brain forced to fend for itself. 


\section{The Empirical Methodology of Neuroeconomics}

One of the basic historical divides between psychologists and economists has been the reluctance of the latter to embrace latent variables in their modeling. In discussions by both psychologists and economists, along with philosophers, of methodologies for modeling choices of individuals, it is often taken for granted that the only grounds for abstemiousness must be residual behaviorism on the part of the economists. We think that a judicious dash of behaviorism is well advised (Ross (2005)), but let us put that aside here. Even economists who are convinced by the fashionable claim that behaviorism is a wholly pernicious doctrine should recognize that introducing latent variables must necessarily involve them in an issue around the nature of 'constructs' which their usual methods allow them to avoid.

The issue in question is the distinction between 'reflective' and 'formative' constructs. The former are diagnosed or indicated by sets of observable markers which are each supposed to perfectly reflect a single underlying latent variable. Such constructs are based on factor analysis, used to discover high-loading items and reject low-loading ones, rather than on structural modeling. Formative constructs, by contrast, have the logical character of dependent variables in economic models. That is, they summarize the interactions of a range of independent (perhaps causally linked) variables. Consider, for example, the construct 'addiction'. A reflective version of this construct would include behavioural tendencies, each of which is taken to indicate the underlying latent condition. In classifying addicts, it is inappropriate to sum the items in the reflective construct, since displaying more reflective items is not associated with being more severely addicted. By contrast, a formative 'addiction' construct would list variables that are taken to structurally constitute addiction. Structural, possibly causal, relationships among these variables are expected to track the extent to which a person is addicted. In the context of research on pathological gambling, which is methodologically representative of much psychological work on clinical conditions, Schellinck and Schrans (2008) complain of a pervasive confusion between reflective and formative constructs, with the former often being borrowed from diagnostic practice when it is the latter that are needed for scientific discovery because they are the basic coin of new generalizations.

This issue doesn't arise for economists, for two reasons. First, their unobservable explanatory variables are often axiomatized by reference to behavioral conditions. Caplin (2008) has drawn attention to the potential value of this for neuroeconomics, and Caplin and Dean (2008) have begun to do something about it. More prosaically, however, the use of standard econometric techniques forces economists to work as if all of their lists of independent variables are formative constructs, because distinct variables in models must not, for the sake of statistical testing, be perfectly correlated with one another. This tends to have the effect of making it hard to find models that both fit wide ranges of data and are econometrically tractable. Though this has sometimes been a subject for complaint, we think it has had a salutary influence on economics. For one thing, it has forced a steady improvement in the depth and sophistication of econometric techniques and theory. This is a good reason why neuroeconomists should wish to remain economists.

They cannot have it both ways, however. If maintenance of modeling discipline recommends the economists' club when key target variables are unobservable as, we will argue, they are in neuroeconomics (fMRI nothwithstanding), then econometric restrictions must be treated seriously. We do not generally find this in BES, however, and we have an 
hypothesis as to why not: fMRI data are frequently treated as if they were first-order observations rather than products of chains of statistical inference. We illustrate this general point with three types of methodological problems that have arisen in recent empirical neuroscience and neuroeconomics.

\subsection{Data Versus Estimates}

The unit of neuroeconomic analysis is a spatial location in the brain emitting signals per unit of time. So in a neuroeconomist's typical fMRI data set a few brains contribute many observations at each point in time, and in a time-series. Therefore, statistical issues arise both for inferences about single brains, and for inferences about pooled samples of brains. To understand the significance of the former, one need only review the typical list of estimation methods employed; for example, see Rabe-Hesketh et al (1997, pp. 217-226). The inferential problem here is simply that point estimates from one stage are taken as data in the next stage, and then there is a long chain of such inferences. The implication is that the standard errors of estimates at later stages tend to overstate the precision of estimations, and later estimates may be completely inconsistent. ${ }^{4}$ This is compounded by the inferential can of worms involved in pooling across brains. There are many different ways to normalize brains, as one can imagine and hope, and these matter for inference. ${ }^{5}$

The end result is that the statistical modeling of neural data is a sequential mixture of limited-information likelihood methods, frequently cobbled together by ad hoc methods: "MacGyver econometrics," to borrow the label of Harrison (2008). Recognizing this fact is not meant as a way of invalidating the clinical or research goals of such exercises, but as a reminder of the extremely limited extent to which modeling and estimation errors are likely to be correctly propagated throughout the chains of inferences based on fMRI data. The end result is often a statistical test in which left hand side and right hand side variables are themselves estimates, often from a long chain of estimates, and are treated as if they are firstorder data. This encourages significant understatement of standard errors on estimates of effects, implying significant overstatement of statistically significant differential activation.

Consider an example of this problem from Glimcher, Kable and Louie (2007). In one instance a correlation is calculated that refers to an econometrically estimated discounted utility function from standard behavioral data. The parameters of this function have standard errors when estimated. But when used to predict activity of the brain, when used as a righthand-side correlate, the standard errors disappear:

These individually measured indifference curves permitted us, for each subject, to model the discounted utility of each delayed option presented to our subjects in the brain scanner. With this behavioral measurement in hand, we could then ask whether any activity in the brain of these subjects was correlated with the discounted utility of an option under consideration. We found that, in each of our subjects, the activity of the brain in three areas typically associated with option valuation [...] showed a clear correlation with this behaviorally derived function. Put another way, brain activity measured

\footnotetext{
${ }^{4}$ This point has been made in the neuroscience literature by Vul, Harris, Winkielman and Pashler (2009), and in a critique of the neuroeconomics literature by Harrison (2008).

${ }^{5}$ Harrison (2008, p. 312ff) provides references to the literature.
} 
in [three areas] ... had many of the properties of that subject's discounted utility function (p. 143).

We flag this problem precisely because we are partial to the authors' underlying algorithmic hypotheses about discounting behavior. It is most important to be critical of stories one finds most plausible, since others can be counted on for the rest.

\subsection{Reverse inference}

The other general problem is related, and is known in the literature as the reverse inference problem. This arises when activations in regions of the brain are presumed to identify the activation of a (labelled) cognitive process. Poldrack (2006) explains the process well, and provides some well-cited illustrations of the extent of the problem.

There is much debate in neuroscience about the selectivity of cognitive processes. D'Esposito et al (1998) give an early discussion of the reverse inference problem in this context. They "conclude that human lateral prefontal cortex supports processes in addition to working memory. Thus, reverse inference of the form 'if prefontal cortex is active, working memory is engaged' is not supported" (p. 274). Claims of this sort are subject to debate and, of course, refinement through different designs, instrumentation and methods of statistical inference. It is not hard to find such debates in neuroscience, but they tend to be glossed in the very neuroeconomics work that should be using the sophisticated modelling strategies of economics to develop tests of them.

Kahneman (2009, pp. 523-524) provides insight into the tendency in the neuroeconomics literature to avoid discussing awkward statistical issues, such as those posed by the reverse inference problem. He reflects on the problem that researchers face, in exactly the way that is relevant for the accumulation of knowledge in this area, when one must evaluate a favored story:

High correlations between well-identified psychological and neural measures are the exception, not the norm. In most experiments ... the correspondence between psychological terms and neural measures is more equivocal, and the interpretation of imaging results is tricky. Poldrack [...] has drawn attention to the problem of "reverse inference," which arises when people infer a specific a psychological process from activity in a particular region -- for example, when activity in dorsal striatum is interpreted as an indication that people enjoy punishing strangers who have behaved unfairly [...]. There is indeed a problem, because activity in dorsal striatum is not perfectly correlated with enjoyment: many other circumstances produce activity in that region, and there is no assurance that it will be active whenever the individual experiences pleasure. In spite of this difficulty, the result and its proposed interpretation is just what a general psychologist (not a neuroscience specialist) would order. It is surprising but plausible, and it drives thinking in new directions. The more difficult test, for a general psychologist, is to remember that the new idea is still a hypothesis which has passed only a rather low standard of proof. I know the test is difficult, because I fail it: I believe the interpretation, and do not label it with an asterisk when I think about it. And I will be sorry if it is disproved, but will have no difficulty in 
accepting its demise -- it would join a long list of defunct once-cherished ideas.

An example of a neuroeconomist acknowledging the importance of the problem is Phelps (2009, pp.245-247). She points out that the amygdala and the insular cortex, two regions often flagged as "proving" that emotions play a role in economic decision-making have been identified as playing other, arguably non-emotional roles. She correctly concludes (p. 247) that "[a]lthough reverse inference is a powerful technique for generating hypotheses and ideas that inspire additional studies or measurements, its use as a primary technique for determining a role for the emotions is questionable." In light of this, we don't quite see what licenses her general conclusion about the role of neuroscience in demonstrating an empirical role for emotions in economic decision-making: "Although emotion was considered an important variable in economic decision making prior to neuroeconomics [...], the recent growth in this field has highlighted a role for emotion in economic choice." (p.234). We do not quarrel with the highly plausible conclusion. We simply can't find new evidence for it coming from neuroeconomics, even in a careful survey precisely intended to summarize that contribution.

The problem afflicts BES to a greater extent than it does NE, partly because the former is more reliant on fMRI work with humans whereas the empirical foundations of the latter lie in single-cell recordings in rats and monkeys. Indeed, we find a nice example of leading NE researchers invoking the problem against a frequently cited flagship BES result. Glimcher (2009, pp. 518-519) criticizes the claim of McClure et al (2004) that an identifiable part of the brain implements the $\beta$ part of the quasi-hyperbolic discounting model and another part of the brain implements the $\delta$ part of that model. He initially questions the anatomical viability of the proposed localization of brain activity, and the lack of correspondence to well-studied animal data. But his most telling criticism is that two of the regions that have been identified as being associated with "emotional" decision-making in these particular tests, the basal ganglia and the medial prefrontal cortex, have also been shown by others to be associated with traditionally "rational" functions such as the encoding of monetary and primary rewards, and the expression of ordinal preference.

\subsection{Sorting Out Shadows}

Another issue of significance in recent debate over the use of fMRI imaging is the problem of "pre-emptive blood flow" identified by Sirotin and Das (2009) and summarized by Leopold (2009). The phenomenon was detected by independently and directly measuring blood flow and neural activity in monkeys. The inferential problem arises if there is blood flow activity in anticipation of some event even if the event does not occur. Some mismatch between blood flow and neural activity is expected, but the difference here is several orders of magnitude beyond the customary. One conjecture is that this is a type of "priming" activity in the brain, so that blood is ready and available in the expectation that it will be used. But since the temporal connection between stimulus and response lies at the heart of almost all neuroeconomic methods, this finding is extremely troublesome. It is particularly likely to be a problem for neuroscientific research involving humans, who can learn vast networks of anticipation from their cultures. 


\section{Conclusion}

BES-style neuroeconomics is plagued by two problems. First, it inherits from behavioural economics an over-emphasis on individual "inboard" choice, divorced from socially scaffolded context, as the basic subject matter of economics. Second, statistical problems that are debated in the neuroscience literature, and which are familiar to econometricians, simply have to be resolved before claims of typical BES strength can be regarded as justified. Advocates of BES cannot simply put them to one side as "footnote qualifications" while they get on with telling interesting stories, a tendency we find in their literature. ${ }^{6}$

We reject the view that neural data are irrelevant to economics as wilfully and obstructively isolationist. But we also reject the free-disposability view that any data is useful data until proven otherwise, implying that we should just collect it anyway and decide later if it was useful. That is a poor model for advancement of study in any field. We welcome NE as a potential contributor to formal modelling of the processes by which agents make economic decisions, though we emphasize that this project is in its infancy and depends on an empirical hypothesis that might turn out to be wrong - that there is a common currency of valuation in the brain. We advise neuroeconomists to remember that and why there is a border between economics and psychology, however often they commute across it.

\footnotetext{
${ }^{6}$ For example, see Fox and Poldrack (2009, p.166), who mention the reverse inference problem developed so well by Poldrack (2006), but simply move on without a blink.
} 


\section{References}

Ainslie, G. (1992). Picoeconomics. Cambridge: Cambridge University Press.

Andersen, S.; Harrison, G.W.; Lau, M.I., and Rutström, E.E. (2008). Eliciting Risk and Time Preferences. Econometrica 76(3): 583-618.

Bénabou, R., and Tirole, J. (2004). Willpower and personal rules. Journal of Political Economy 112: 848-886.

Benhabib, J., and Bisin, A. (2004). Modeling internal commitment mechanisms and selfcontrol: A neuroeconomics approach to consumption-saving decisions. Games and Economic Behavior 52: 460-492.

Bernheim, B.D. (2009). On the potential of neuroeconomics: a critical (but hopeful) appraisal. American Economic Journal: Microeconomics. Forthcoming

Camerer, C., Loewenstein, G., and Prelec, D. (2005). Neuroeconomics: how neuroscience can inform economics. Journal of Economic Literature 43: 9-64.

Caplin, A. (2008). Economic theory and psychological data: Bridging the divide. In A. Caplin and A. Schotter, eds., The Foundations of Positive and Normative Economics: A Handbook, pp. 336371. Oxford: Oxford University Press.

Caplin, A., and Dean, M. (2008). Dopamine, Reward Prediction Error, and Economics. Quarterly Journal of Economics 123(2): 663-701.

Caplin, A., and Schotter, A. (2008) Eds., The Foundations of Positive and Normative Economics: A Handbook, Oxford: Oxford University Press.

Clark, A. (1997). Being There. Cambridge, MA: MIT Press.

Coller, M.; Harrison, G.W., and Rutström, E.E. (2009). Latent process heterogeneity in discounting behavior. Working Paper 09-04, Department of Economics, College of Business Administration, University of Central Florida, 2009.

D’Esposito, M.; Ballard, D.; Aguirre, G. K., and Zarahn, E. (1998). Human Prefrontal Cortex Is Not Specific for Working Memory: A Functional MRI Study. NeuroImage 8: 274282.

Fox, C.R., and Poldrack, R.A. (2009). Prospect Theory and the Brain. In P. Glimcher, C. Camerer, E. Fehr and R. Poldrack, eds., Neuroeconomics: Decision Making and the Brain, pp. 145173. London: Elsevier.

Fudenberg, D., and Levine, D.K. (2006). A dual self model of impulse control. American Economic Review 96: 1449-1476.

Glimcher, P. (2003). Decisions, Uncertainty and the Brain. Cambridge, MA: MIT Press.

Glimcher, P. (2009). Choice: towards a standard back-pocket model. In P. Glimcher, C.

Camerer, E. Fehr and R. Poldrack, eds., Neuroeconomics: Decision Making and the Brain, pp. 503521. London: Elsevier. 
Glimcher, P.W.; Kable, J., and Louie, K. (2007) Neuroeconomic Studies of Impulsivity: Now or Just as Soon as Possible? American Economic Review (Papers \& Proceedings) 97(2): 142-147.

Gode, D., and Sunder, S. (1993). Allocative Efficiency of Markets with Zero-Intelligence Traders: Market as a Partial Substitute for Individual Rationality. Journal of Political Economy 101(1): 119-137.

Gul, F., and Pesendorfer, W. (2001). Temptation and self-control. Econometrica 69: 14031436.

Gul, F., and Pesendorfer, W. (2008). The case for mindless economics. In A. Caplin and A. Schotter, eds., The Foundations of Positive and Normative Economics: A Handbook, pp. 3-39. Oxford: Oxford University Press.

Harrison, G.W. (2008). Neuroeconomics: A critical reconsideration. Economics and Philosophy 24: 303-344.

Harrison, G.W.; Lau, M.I., and Williams, M.B. (2002). Estimating Individual Discount Rates for Denmark: A Field Experiment. American Economic Review 92(5): 1606-1617.

Harrison, G.W., and Rutström, E.E. (2008). Risk Aversion in the Laboratory. In J.C. Cox and G.W. Harrison, eds., Risk. Aversion in Experiments, pp. 41-196. Bingley, UK: Emerald.

Harrison, G.W., and Rutström, E.E. (2009). Representative Agents in Lottery Choice Experiments: One Wedding and A Decent Funeral. Experimental Economics, 12(2): 133-158.

Hutchins, E. (1995) Cognition in the wild. Cambridge, MA: MIT Press.

Kahneman, D. (2008). Remarks on neuroeconomics. In P. Glimcher, C. Camerer, E. Fehr and R. Poldrack, eds., Neuroeconomics: Decision Making and the Brain, pp. 523-526. London: Elsevier.

Knutson, B., Rick, S., Wimmer, G.E., Prelec, D., \& Loewenstein, G. (2007). Neural predictors of purchases. Neuron, 53: 147-156.

Leopold, D.A. (2009). Pre-emptive blood flow. Nature 457: 387-388.

McClure, S., Laibson, D., Loewenstein, G., and Cohen, J. (2004). Separate neural systems value immediate and delayed monetary rewards. Science 306: 503-507.

Phelps, E.A. (2008). The study of emotions in neuroeconomics. In P. Glimcher, C. Camerer, E. Fehr and R. Poldrack, eds., Neuroeconomics: Decision Making and the Brain, pp. 523-526.

London: Elsevier.

Poldrack, R.A. (2006). Can Cognitive Processes by Inferred from Neuroimaging Data? Trends in Cognitive Science 10: 59-63.

Poldrack, R.A., and Wagner, A.D. (2004). What Can Neuroimaging Tell Us About the Mind? Insights from Prefontal Cortex. Current Directions in Psychological Science 13(5): 177-181. 
Rabe-Hesketh, S.; Bullmore, E.T., and Brammer, M.J., "The Analysis of Functional Magnetic Resonance Images," Statistical Methods in Medical Research, 1997, 6, 215-237.

Ross, D. (2005). Economic Theory and Cognitive Science: Microexplanation. Cambridge, MA: MIT Press.

Ross, D. (2008). Two Styles of Neuroeconomics. Economics and Philosophy 24: 473-483.

Ross, D., Sharp, C., Vuchinich, R., and Spurrett, D. (2008). Midbrain Mutiny. Cambridge, MA: MIT Press.

Schellinck, T., and Schrans, T (2008). Screening With Meaning: New Directions in the Development of Gambling Risk Measures. http://www.assissa.eu/easg/thursday/1400ses4/schellinck tony.pdf. Accessed 1 June 2009.

Schelling, T. (1978). Economics, or the art of self-management. American Economic Review. 68: 290-294.

Schelling, T. (1980). The intimate contest for self-command. Public Interest. 60: 94-118.

Schelling, T. (1984). Self-command in practice, in policy, and in a theory of rational choice. American Economic Review. 74: 1-11.

Sirotin, Y.G., and Das, A. (2009). Anticipatory haemodynamic signals in sensory cortex not predicted by local neuronal activity. Nature 457: 475-479.

Smith, V. (2007). Rationality in Economics. Cambridge: Cambridge University Press.

Strotz, R.H. (1955-56). Myopia and Inconsistency in Dynamic Utility Maximization. The Review of Economic Studies 23(3): 165-180.

Sunder, S. (2003). Market as Artifact: Aggregate Efficiency from Zero Intelligence Traders. In M. Augier and J. March, eds., Models of a Man: Essays in Memory of Herbert A. Simon, pp. 501-519. Cambridge, MA: MIT Press.

Vul, E.; Harris, C.; Winkielman, P., and Pashler, H. (2009). Puzzlingly High Correlations in fMRI Studies of Emotion, Personality, and Social Cognition. Perspectives on Psychological Science. 4(3): 274-290.

Wilcox, N. (2008). Against simplicity and cognitive individualism. Economics and Philosophy 24(3): 523-532. 